\title{
CARBONO, NITROGÊNIO, FÓSFORO E ENXOFRE EM SOLOS TRATADOS COM COMPOSTO DE LIXO URBANO(1)
}

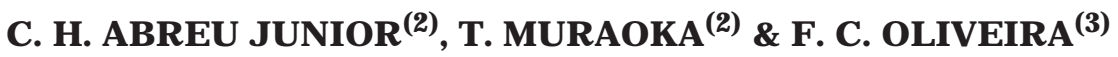

\begin{abstract}
RESUMO
Foram estudados os efeitos da aplicação de composto de lixo urbano, proveniente da usina de compostagem São Matheus da cidade de São Paulo, na dose de $30 \mathrm{~g} \mathrm{dm}^{-3}\left(60 \mathrm{t} \mathrm{ha}^{-1}\right)$, na presença e ausência de calcário dolomítico eadubos minerais, sobre os teores de carbono orgânico, de nitrogênio total e de fósforo e enxofre disponíveis de 21 solos ácidos e cinco solos alcalinos, onde o calcário foi substituído por gesso. O experimento foi realizado em condições de casa de vegetação com os solos nas parcelas em blocos ao acaso, com três repetições e os tratamentos em subparcelas. 0 acúmulo de matéria orgânica, em virtude da aplicação do composto, foi evidente em solos com teores iniciais de carbono orgânico $>12 \mathrm{~g} \mathrm{dm}^{-3}$ e de nitrogênio $>1,3 \mathrm{~g} \mathrm{dm}^{-3}$, porém com relação $\mathrm{C} / \mathrm{N}<12$. Nos demais solos, o acúmulo foi decorrente da interação entre a estabilidade da matéria orgânica do composto, da matéria orgânica nativa e as propriedades físicas e químicas dos solos. A aplicação do composto aumentou os teores de nitrogênio total e de enxofre disponível em todos os solos, porém o fósforo disponível somente foi aumentado nos solos ácidos. A aplicação do composto de lixo urbano como fertilizante orgânico é viável, porém seus efeitos sobre as propriedades químicas do solo devem ser monitorados.
\end{abstract}

Termos de indexação: adu bação orgânica, di sponibilidade de nutrientes, matéria orgânica do solo, mineralização e imobilização de nutrientes.

(1) Parte da Tese de Doutorado do primeiro autor, apresentada ao Curso de Pós-Graduação em Solos e Nutrição de Plantas, Escola Superior de Agricultura “Luiz de Queiroz" - ESALQ/USP. Financiado parcialmente pela FAPESP. Recebido para publicação em julho de 2001 e aprovado em março de 2002.

(2) Professor do Centro de Energia Nuclear na Agricultura, Universidade de São Paulo - USP. Caixa Postal 96, CEP 13400-970 Piracicaba (SP). E-mail: cahabreu@cena.usp.br; muraoka@cena.usp.br

(3) Engenheiro-Agrônomo, Doutor, Biossolo Agricultura \& Ambiente S.C. Ltda. Rua Edú Chaves 822, São Dimas, CEP 13416-020 Piracicaba (SP). E-mail: fernando@biossolidos.com.br 


\title{
SUMMARY: ORGANIC CARBON, NITROGEN, PHOSPHORUS, AND SULFUR I N SOILS AMENDED WITH SOLID URBAN WASTE COMPOST
}

\begin{abstract}
A green house experiment was conducted to investigate the effects of the application of solid urban waste compost at a rate of $30 \mathrm{~g} \mathrm{dm}^{-3}\left(60 \mathrm{t} \mathrm{ha}^{-1}\right)$, on 21 acid and five alkaline soils in relation to their organic carbon, total nitrogen, available phosphorous and sulfur contents. Compost from theSão Matheus Treatment Plant (São Paulo, Brazil) was applied with or without dol omi tic limeand mineral fertilizers. In al kalinesoils, limewas substituted by gypsum. Theexperiment was carried out with soils in thepl ots, in a completely randomized block design with three replicates, and treatments in the sub-plots. Compost application caused evident organic carbon accumulation in soils with initial organic carbon contents $>12 \mathrm{~g} \mathrm{dm}^{-3}$ and nitrogen $>1.3 \mathrm{~g} \mathrm{dm}^{-3}$, but a $\mathrm{C} / \mathrm{N}$ ratio $<12$. In the other soils, organic carbon accumulation was a consequence of the interaction between thestability of compost organic matter, original organic matter, and physical and chemical soil properties. Residue application increased the contents of total nitrogen and available sulfur in all soils, but availablephosphorous only increased in acid soils. Theuse of solid urban wastecompost as organic fertilizer in agricultural areas is viabl eunder the condition, however, that its effects on chemical properties are properly monitored.

Index terms: organic fertilization, nutrient availability, soil organic matter, nutrient mineralization and immobilization.
\end{abstract}

\section{NTRODUÇÃO}

A presença de materiais orgânicos no lixo domiciliar, ricos em nutrientes recicláveis, indica enorme potencialidade desse material para ser empregado na produção de adubo orgânico, por técnicas de compostagem, para uso na agricultura, contribuindo para a gestão dos resíduos sólidos orgânicos gerados nas cidades (Kiehl, 1985; Xin et al., 1992; Oliveira, 2000).

Os principais efeitos da aplicação de composto sobre as propriedades quími cas do sol o são: el evação do pH edoteor dematéria orgânica, redução da acidez potencial e trocável, aumentos na disponibilidade de nitrogênio, fósforo, cálcio, magnésio e potássio (Hortenstine \& Rothwell, 1972; Mazur et al., 1983; Ferro Neto, 1994; Alves et al., 1999; Abreu J r. et al., 2000; Oliveira, 2000).

De acordo com Berton \& Valadares (1991), o elevado teor de matéria orgânica em compostos de lixo (190 a $530 \mathrm{~g} \mathrm{~kg}^{-1}$ ) é fator preponderante para se justificar o uso agrícola desses materiais, não obstante o teor de nitrogênio total também ser considerável (10 a $\left.15 \mathrm{~g} \mathrm{~kg}^{-1}\right)$. A aplicação de composto deverá proporcionar o aumento do teor de carbono orgânico e contribuir para a melhoria das propriedades biológicas, físicas e químicas do solo.

Trabalho realizado em conjunto pela CETESB, de Novo Horizonte, e a UNESP, de J aboticabal, mostrou que a aplicação de $30 \mathrm{t} \mathrm{ha}^{-1}$ de um vermi composto aumentou o teor de matéria orgânica do sol o em 15 \% (Ferro Neto, 1994). Oliveira (2000), estudando os efeitos da aplicação sucessiva de composto de lixo, nas doses de 0, 20, 40 e 60 t ha-1, $^{-1}$ no ano agrícola de 1996/97, e de 0, 24, 48 e 78 t ha-1, no ano agrícola de 97/98, sobre as propriedades químicas de um solo cultivado com cana-de-açúcar, verificou que o teor de carbono orgânico apresentou aumento linear, conforme as doses do composto, dos 30 aos 360 dias após a incorporação do resíduo, durante os dois anos agrícolas. Ao final do segundo ano agrícola, esse autor observou para as doses acúmulos de carbono da ordem de 18, 29 e $55 \%$ em relação aos teores observados na testemunha.

A aplicação conjunta de composto de lixo e fertilizante nitrogenado tem acarretado efeitos na disponibilidade de nitrogênio do sol o e na nutriçãoe produção vegetal superiores aos efeitos de ambas as fontes isoladamente (Sikora \& Azam, 1993). Conforme Sikora \& Yakovchenko (1996), esse sinergismo deveser decorrente da mineral ização do material orgânico adicionado e não da matéria orgânica nativa do solo. Todavia, a taxa de degradação do composto de lixo e a mineralização de nutrientes são dependentes do seu grau de maturação (Xin et al., 1992; Cardoso et al., 1995; Bernal et al., 1998; Oliveira, 2000).

Mazur et al . (1983) constataram aumento de $57 \%$ noteor defósforo disponível pela aplicação decomposto delixo em um $L$ atossol oA marel o com teor inicial de $1 \mathrm{mg} \mathrm{dm}^{-3}$ deP. Alves et al . (1999) verificaram, num PodzólicoVermel ho-Amarelo com $2 \mathrm{mg} \mathrm{dm}^{-3}$ deP, um efeito linear de doses de composto ( 0 a $\left.100 \mathrm{t} \mathrm{ha}^{-1}\right)$ sobre os teores de fósforo quando na ausência de adubo mineral (N-P-K-S + micronutrientes); porém, na presença de adubo, o efeito de doses foi quadrático.

O efei to de composto delixo sobre a disponibilidade de enxofre no solo, embora deva estar diretamente relacionado com a dose de aplicação do composto, não tem sido objeto de estudo. Tabatabai \& Chae 
(1991) verificaram que a mineralização a sulfatos no solo pela aplicação de 50 t ha-1 de lodo de esgoto éintensa nas primeiras seis semanas de incubação, porém diminui de intensidade entre a sexta e a vigésima sexta semana.

Este trabalho foi desenvolvido com a finalidade de estudar os efeitos da aplicação de composto de lixo, na presença e ausência de cal cário e de adubos minerais, sobre os teores de carbono orgânico, de nitrogênio, de fósforo e de enxofre em solos de diferentes regiões do Brasil.

\section{MATERIAL E MÉTODOS}

O experimento foi realizado em casa de vegetação, no Centro de Energia Nuclear na Agricultura (CENA/USP), em Piracicaba (SP), utilizando vasos plásticos com $1,1 \mathrm{dm}^{3}$ de amostras retiradas da camada de 0-20 cm de 21 sol os ácidos e de cinco solos al cal inos de diferentes regiões do Brasil (Quadro 1). As amostras utilizadas no experimento foram secas ao ar, passadas em peneira de $2 \mathrm{~mm}$ de malha, armazenadas eanal isadas quimicamente(Quadro 2).
Foi utilizado composto de lixo urbano, com quatro meses de compostagem, coletado na usina de compostagem São Matheus, no município de São Paulo (SP). Amostras do composto foram secas ao ar, passadas em peneira de $4 \mathrm{~mm}$ de malha e homogeneizadas para ouso no experimento. A análise química do composto revel ou os seguintes resultados: umidade $=390 \mathrm{~g} \mathrm{~kg}^{-1} ; \mathrm{pH}$ em água = 7,96; condutividade elétrica $=7,25 \mathrm{dS} \mathrm{m}^{-1}$; teores de carbono total e orgânico $=253$ e $186 \mathrm{~g} \mathrm{~kg}^{-1}$; teores totais em $\mathrm{g} \mathrm{kg}^{-1}$ de nitrogênio $=13,3$; fósforo $=3,1$; potássio $=12,2$; cál cio $=28,6$; magnésio $=4,0$; en xofre $=9,2$; sódio $=8,5$ ealumínio $=20,9$. Os valores de $\mathrm{pH}$ e condutividade elétrica $\left(a 25^{\circ} \mathrm{C}\right.$ ) foram medidos em água, empregando-se a relação composto/água de 1:4 $(\mathrm{p} / \mathrm{v})$, após 5 minutos de agitação vigorosa e $1 \mathrm{~h}$ de repouso; o carbono total, pelo método da combustão por via seca, utilizando-se o equi pamento LECO CR412, e o carbono orgânico, por dicromatometria de oxirredução com determinação por colorimetria (adaptado deRaij et al., 1987); onitrogênio total, pelo método micro-Kjeldahl em extrato de digestão sulfúrica, e os teores totais dos demais elementos, por espectrometria de emissão atômica em plasma induzindo (ICP-AES) em extrato de digestão com $\mathrm{HCl}, \mathrm{HClO}_{4}$ e HF.

\section{Quadro 1. Classificação e procedência dos solos utilizados no experimento}

\begin{tabular}{|c|c|c|c|}
\hline Sigla & Classe de solo(1) & Município & E stado \\
\hline \multicolumn{4}{|c|}{ Solos ácidos } \\
\hline GX & Gleissolo Háplico Tb distrófico & Iranduba & $A M$ \\
\hline RQ-1 & N eossolo Quartzarênico distrófico & Paraipabas & $\mathrm{CE}$ \\
\hline LA-1 & L atossolo Amarelo acriférrico & Viçosa & MG \\
\hline LV-1 & L atossolo Vermel ho distroférrico & Três Lagoas & MS \\
\hline LV -2 & Latossolo Vermel ho acriférrico & Cuiabá & $\mathrm{MT}$ \\
\hline LA-2 & Latossolo Amarelo distrófico & Capitão Poço & PA \\
\hline PVA-1 & Argissolo Vermel ho-Amarelo distrófico & Capitão Poço & PA \\
\hline $\mathrm{LA}-3$ & Latossolo Amarelo distrófico & I pixuna & PA \\
\hline LA-4 & Latossolo Amarelo distrófico & I pixuna & PA \\
\hline NV-1 & Nitossolo Vermelho distroférrico & Maringá & $P R$ \\
\hline LA-5 & Latossolo Amarelo distrófico argissólico & Ariquemes & RO \\
\hline PVA-2 & Argissolo Vermelho-Amarelo distrófico & Ariquemes & RO \\
\hline LA-6 & Latossolo A marelo E utrófico argissólico & $\mathrm{N}$ ão identificado & $\mathrm{SC}$ \\
\hline PVA-3 & Argissolo Vermel ho-Amarelo distrófico & Capão Bonito & SP \\
\hline LV-3 & Latossolo Vermelho acriférrico & Guatapará & SP \\
\hline LV -4 & Latossolo Vermelho distrófico & Piracicaba & $\mathrm{SP}$ \\
\hline PV & Argissolo Vermelho distrófico & Piracicaba & SP \\
\hline PVA-4 & Argissolo Vermelho-Amarelo distrófico & Piracicaba & SP \\
\hline NV-2 & Nitossolo Vermelho distrófico & Piracicaba & SP \\
\hline RQ-2 & N eossolo Quartzarênico distrófico & São Pedro & SP \\
\hline LVA-1 & Latossolo Vermelho-Amarelo distrófico & Três Barras & $\mathrm{SP}$ \\
\hline \multicolumn{4}{|c|}{ Solos alcalinos } \\
\hline$C X-1$ & Cambissolo Háplico Ta eutrófico & Irecê & $\mathrm{BA}$ \\
\hline$C X-2$ & Cambissolo Háplico Ta E utrófico vértico & Irecê & $\mathrm{BA}$ \\
\hline LA-7 & Latossolo Amarelo eutrófico & Irecê & $\mathrm{BA}$ \\
\hline LVA-2 & Latossolo Vermelho-Amarelo eutrófico & Irecê & BA \\
\hline SS & Salino-Sódico & Souza & PB \\
\hline
\end{tabular}

(1) Sistema brasileiro de classificação de sol os (E mbrapa, 1999). 
Quadro 2. Características químicas das amostras dos solos utilizados, retiradas na camada de 0-20 cm de profundidade

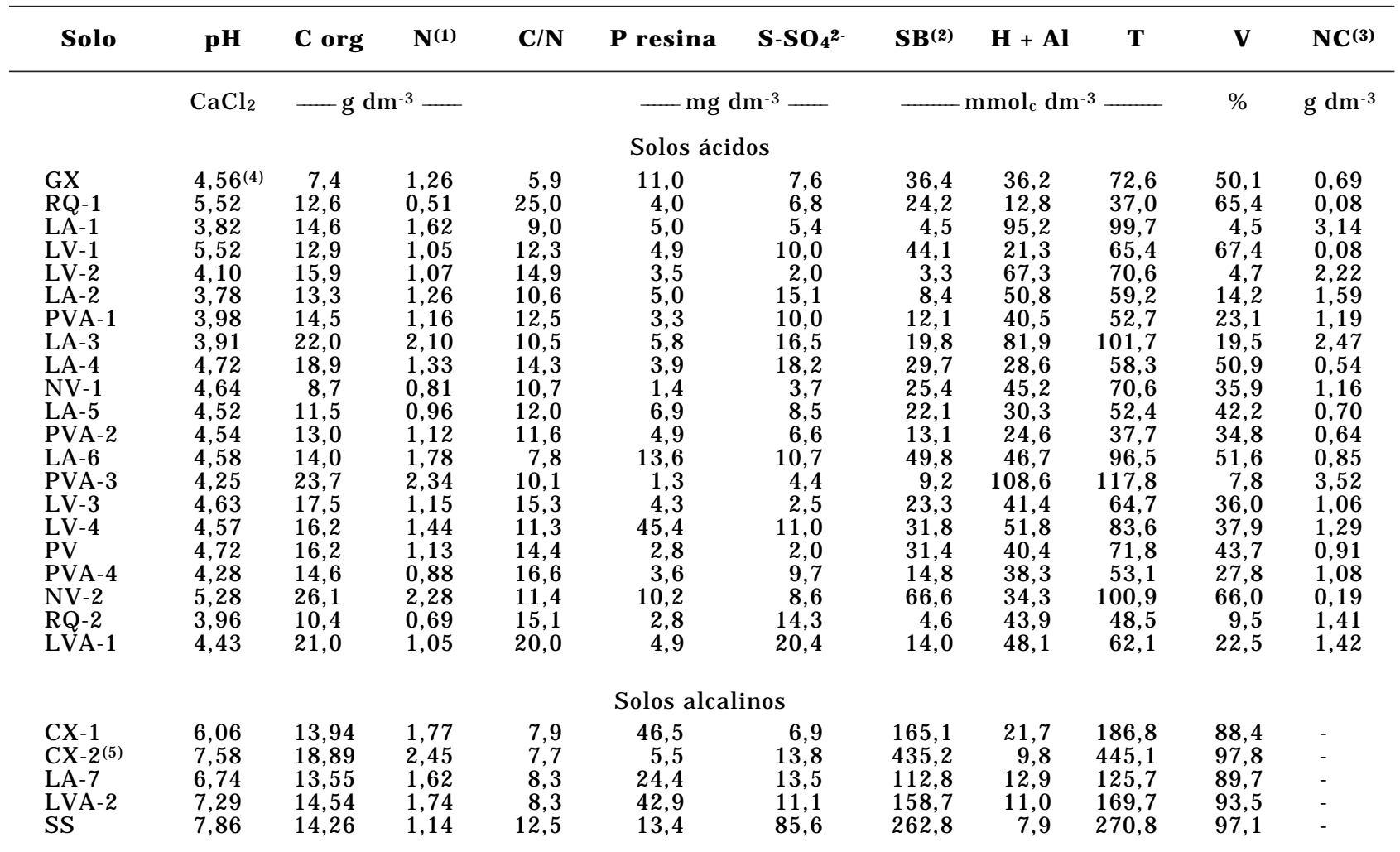

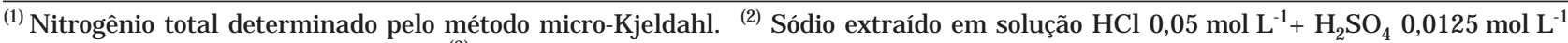
na relação solo/extrator de 1:5 (v/v). ${ }^{(3)}$ Necessidade de calagem, demais análises químicas e cál culos, conforme descrito em Raij et al. (1987). ${ }^{(4)}$ Média de três repetições. ${ }^{(5)}$ Presença de carbonatos livres.

Nos solos ácidos, foram aplicados os seguintes tratamentos: composto, composto +adubo, composto + cal cário, composto + calcário + adubo, cal cário + adubo e testemunha. As amostras dos solos, nos respectivos tratamentos, receberam calcário dolomítico (PRNT de $104 \%$ ) suficiente para elevar a saturação por bases a 70 \% (Quadro 2) e, após homogeneização da amostra com o calcário, água destilada-deionizada suficiente para atingir umidade de $60 \%$ da capacidade de retenção deágua. Os vasos foram incubados por 30 dias, mantendo-se as condições de umidade com pesagem e rega diárias. Nos sol os al cal inos, foram aplicados, em substituição ao cal cário, $3 \mathrm{~g} \mathrm{dm}^{-3}$ ( $\left.6 \mathrm{t} \mathrm{ha}^{-1}\right)$ de gesso, correspondente a $25 \%$ da necessidade máxima de gesso para a correção do solo Salino-Sódico (Santos, 1995).

Após a incubação e interrupção da rega, foram adicionados ehomogeneizados às amostras dos sol os, nos respectivos tratamentos, o composto de lixo urbano na dose de $30 \mathrm{~g} \mathrm{dm}^{-3}$ (60 t ha-1), na base de peso seco, e o adubo mineral. Os macronutrientes N, P e K foram aplicados nas doses de 100, 150 e $100 \mathrm{mg} \mathrm{dm}^{-3}$ (equival entes a 200, 300 e $200 \mathrm{~kg} \mathrm{ha}^{-1}$ ), nas formas de uréia, superfosfato simples (que também serviu como fonte de enxofre) e cloreto de potássio, e os micronutrientes $\mathrm{B}, \mathrm{Cu}, \mathrm{Fe}, \mathrm{Mn}, \mathrm{Mo} \mathrm{e}$ $\mathrm{Zn}$, na forma de sol ução nutritiva $\left(\mathrm{H}_{3} \mathrm{BO}_{3}, \mathrm{CuCl}_{2}, \mathrm{Fe}-\right.$ EDTA, $\mathrm{MnCl}_{2}, \mathrm{MoO}_{3}$ e $\mathrm{ZnCl}_{2}$ ), nas doses de $1 ; 1 ; 3$; 2,5; 0,05 e 2,5 $\mathrm{mg} \mathrm{dm}^{-3}$ (equival entes a 2, 2, 6, 5, 0,1 e $\left.5 \mathrm{~kg} \mathrm{ha}^{-1}\right)$, respectivamente.

Após a aplicação dos tratamentos, as amostras de sol os receberam água e foram incubadas por mais 30 dias, para permitir a reação dos materiais adicionados às amostras. Concluída a incubação, após inter rupção da rega e secagem das amostras de sol o, foram coletados aproximadamente $130 \mathrm{~cm}^{3}$ deterra de cada vaso para aval iação dos efeitos dos tratamentos.

As amostras deterra foram secas ao ar, passadas em peneira com abertura de 0,5 mm e submetidas à análise de carbono orgânico por método col orimétrico; fósforo disponível foi extraído por resina aniônica, conforme métodos descritos em Raij et al. (1987); nitrogêniototal em extrato de digestão sulfúrica, pelo método micro-Kjeldahl, e enxofre disponível na forma de sulfato, extraído com $\mathrm{CaCl}_{2} 0,01 \mathrm{~mol} \mathrm{~L}^{-1} \mathrm{e}$ dosado por turbidimatria (Vitti, 1988). 
O delineamento experimental foi em blocos ao acaso, com os sol os em parcelas com três repetições, tanto para solos ácidos quanto alcalinos e os tratamentos em subparcelas. Para verificar a necessidade de transformação dos dados e para análise de correlação, utilizou-se o programa SAS/SAS Lab (SAS, 1998) e, para a análise de variância e teste de médias, o programa SANEST (Zonta et al., 1987).

\section{RESULTADOS E DISCUSSÃO}

\section{Carbono orgânico}

A aplicação isolada do composto de lixo urbano nos solos ácidos aumentou os teores de carbono orgânico de 1,2 (PVA-1 e RQ-2) a 5,5 g dm³ (LV-4) (Quadro 3), com um incremento médio de $20 \%$ em relação à testemunha, resultante de sua carga orgânica. Todavia, esse efeito do composto nos teores de carbono não foi significativo em $48 \%$ dos solos.

A degradação do composto de lixo é reduzida à medida que aumenta seu grau de maturação (Xin et al., 1992; Bernal et al., 1998). Consi derando a relação $\mathrm{C} / \mathrm{N}$ do composto, que era de 19, pode-se considerálo como um composto com fração humificada estável, pouco susceptível à degradação rápida em curto período (Xin et al., 1992) e com el evado potencial de acúmul o no sol o (Ferro N eto, 1994; Alves et al., 1999; Oliveira, 2000).

A aplicação do composto aumentou o teor de carbono orgânico nos solos ácidos com teor inicial desse el emento superior a $12 \mathrm{~g} \mathrm{dm}^{-3}$ e de nitrogênio superior a $1,3 \mathrm{~g} \mathrm{dm}^{-3}$, porém com relação $\mathrm{C} / \mathrm{N}$ inferior a 12 (ex. LA-1, LA-2, LA-3, LA-6, LV-4 e NV-2) (Quadros 2 e 3), provavel mente em conseqüência de sua matéria orgânica estável com menor degradação da carga orgânica adicionada. NosoloPVA-3, embora

Quadro 3. Teores de carbono orgânico em solos ácidos, adubados com composto de lixo em combinação com calcário e adubos mi nerais, e em solos alcalinos, nos quais o calcário foi substituído por gesso

\begin{tabular}{|c|c|c|c|c|c|c|}
\hline \multirow{3}{*}{ Solo } & \multicolumn{4}{|c|}{ Composto de lixo } & \multirow{3}{*}{$\begin{array}{l}\text { Calcário } \\
\text { e adubo }\end{array}$} & \multirow{3}{*}{ Testemunha } \\
\hline & \multicolumn{2}{|c|}{ Sem calcário } & \multicolumn{2}{|c|}{ Com calcário } & & \\
\hline & Sem adubo & Com adubo & Sem adubo & Com adubo & & \\
\hline \multicolumn{7}{|c|}{ Solos ácidos } \\
\hline $\mathrm{GX}$ & $14,2 A^{(1)}$ & $14,8 \mathrm{~A}$ & $12,2 \mathrm{AB}$ & $14,6 \mathrm{~A}$ & $10,7 \mathrm{~B}$ & $12,1 \mathrm{AB}$ \\
\hline RQ-1 & $10,7 \mathrm{~A}$ & $11,0 \mathrm{~A}$ & $10,7 \mathrm{~A}$ & $12,7 \mathrm{~A}$ & $5,8 \mathrm{~B}$ & $5,5 \mathrm{~B}$ \\
\hline LA-1 & $27,1 \mathrm{~A}$ & $25,6 \mathrm{AB}$ & $26,0 \mathrm{~A}$ & $25,0 \mathrm{ABC}$ & $22,9 \mathrm{C}$ & $23,0 \mathrm{BC}$ \\
\hline LV-1 & $18,6 \mathrm{~A}$ & $17,3 \mathrm{~A}$ & $17,7 \mathrm{~A}$ & $19,0 \mathrm{~A}$ & $13,5 \mathrm{~B}$ & $14,2 \mathrm{~B}$ \\
\hline LV -2 & $27,1 \mathrm{~A}$ & $27,9 \mathrm{~A}$ & $26,1 \mathrm{AB}$ & $27,3 \mathrm{~A}$ & $25,4 \mathrm{AB}$ & $24,4 \mathrm{~B}$ \\
\hline LA-2 & $19,8 \mathrm{~A}$ & $19,4 \mathrm{~A}$ & $19,1 \mathrm{~A}$ & $19,1 \mathrm{~A}$ & $14,7 \mathrm{~B}$ & $15,8 \mathrm{~B}$ \\
\hline PVA-1 & $19,2 \mathrm{~A}$ & $18,2 \mathrm{~A}$ & $18,6 \mathrm{~A}$ & $18,8 \mathrm{~A}$ & $17,2 \mathrm{~A}$ & $18,0 \mathrm{~A}$ \\
\hline LA-3 & $30,3 \mathrm{AB}$ & $31,6 \mathrm{~A}$ & $30,9 \mathrm{~A}$ & $31,0 \mathrm{~A}$ & $28,1 \mathrm{BC}$ & $27,0 \mathrm{C}$ \\
\hline LA-4 & $20,4 \mathrm{ABC}$ & $21,2 \mathrm{AB}$ & $21,6 \mathrm{AB}$ & $22,0 \mathrm{~A}$ & $19,1 \mathrm{BC}$ & $17,8 \mathrm{C}$ \\
\hline NV-1 & $12,8 \mathrm{AB}$ & $13,8 \mathrm{AB}$ & $13,6 \mathrm{AB}$ & $15,0 \mathrm{~A}$ & $13,0 \mathrm{AB}$ & $11,1 \mathrm{~B}$ \\
\hline LA-5 & $13,4 \mathrm{AB}$ & $13,2 \mathrm{AB}$ & $13,2 \mathrm{ABC}$ & $15,0 \mathrm{~A}$ & 10,4 BC & $9,9 \mathrm{C}$ \\
\hline PVA-2 & $15,1 \mathrm{~A}$ & $14,7 \mathrm{AB}$ & $14,4 \mathrm{AB}$ & $16,5 \mathrm{~A}$ & $10,8 \mathrm{C}$ & $11,5 \mathrm{BC}$ \\
\hline LA-6 & $22,3 \mathrm{~A}$ & $21,3 \mathrm{~A}$ & $21,7 \mathrm{~A}$ & $22,5 \mathrm{~A}$ & $18,2 \mathrm{~B}$ & 18,4 B \\
\hline PVA-3 & $36,0 \mathrm{~A}$ & $36,0 \mathrm{~A}$ & $36,0 \mathrm{~A}$ & $35,9 \mathrm{~A}$ & $34,7 \mathrm{~A}$ & $34,4 \mathrm{~A}$ \\
\hline LV-3 & $26,9 \mathrm{AB}$ & $27,5 \mathrm{~A}$ & $25,1 \mathrm{AB}$ & $27,1 \mathrm{AB}$ & $26,8 \mathrm{AB}$ & $24,7 \mathrm{~B}$ \\
\hline LV-4 & $24,7 \mathrm{~A}$ & $23,5 \mathrm{~A}$ & $23,5 \mathrm{~A}$ & $22,3 \mathrm{~A}$ & 19,2 B & $19,2 \mathrm{~B}$ \\
\hline PV & $20,9 A B$ & $20,9 \mathrm{AB}$ & $21,0 \mathrm{AB}$ & $21,8 \mathrm{~A}$ & $17,3 \mathrm{C}$ & 18,8 BC \\
\hline PVA-4 & $15,8 \mathrm{AB}$ & $17,7 \mathrm{~A}$ & $17,2 \mathrm{~A}$ & $15,1 \mathrm{AB}$ & $12,9 \mathrm{~B}$ & $14,1 \mathrm{~B}$ \\
\hline NV-2 & $33,2 \mathrm{~A}$ & $30,8 \mathrm{BC}$ & $32,5 \mathrm{AB}$ & $32,5 \mathrm{AB}$ & 29,6 C & $29,4 \mathrm{C}$ \\
\hline $\mathrm{RQ}-2$ & $12,0 \mathrm{AB}$ & $13,2 \mathrm{AB}$ & $14,3 \mathrm{~A}$ & $14,6 \mathrm{~A}$ & $12,3 \mathrm{AB}$ & $10,9 \mathrm{~B}$ \\
\hline LVA-1 & $24,1 \mathrm{AB}$ & $24,9 \mathrm{AB}$ & $23,3 \mathrm{AB}$ & $25,8 \mathrm{~A}$ & $20,4 \mathrm{C}$ & $22,6 \mathrm{BC}$ \\
\hline \multicolumn{7}{|c|}{ Solos alcalinos } \\
\hline$C X-1$ & $21,5 \mathrm{~A}$ & $19,8 \mathrm{AB}$ & $20,4 \mathrm{AB}$ & $19,6 \mathrm{AB}$ & $17,2 \mathrm{~B}$ & $17,0 \mathrm{~B}$ \\
\hline$C X-2$ & $24,1 \mathrm{AB}$ & $23,2 \mathrm{~B}$ & $26,5 \mathrm{AB}$ & $27,6 \mathrm{~A}$ & $19,4 \mathrm{C}$ & $25,4 \mathrm{AB}$ \\
\hline LA-7 & $19,0 \mathrm{~A}$ & $16,6 \mathrm{AB}$ & $16,0 \mathrm{AB}$ & $16,8 \mathrm{AB}$ & $16,0 \mathrm{AB}$ & $14,2 \mathrm{~B}$ \\
\hline LVA-2 & $21,4 \mathrm{~A}$ & $19,2 \mathrm{AB}$ & $21,4 \mathrm{~A}$ & $21,0 \mathrm{AB}$ & $18,6 \mathrm{AB}$ & $17,8 \mathrm{~B}$ \\
\hline SS & $18,0 \mathrm{AB}$ & $16,9 \mathrm{AB}$ & $19,9 \mathrm{~A}$ & $19,1 \mathrm{~A}$ & $15,1 \mathrm{~B}$ & $16,9 \mathrm{AB}$ \\
\hline
\end{tabular}

\footnotetext{
(1) Médias seguidas de mesma letra, nas linhas, não diferem entre si pelo teste Tukey a $5 \%$.
} 
essas condições tenham ocorrido, maior disponibilidade de nitrogênio inorgânico deve ter favorecido a decomposi ção do carbono proveniente do composto.

Quando o teor inicial de carbono for superior a $12 \mathrm{~g} \mathrm{dm}^{-3}$ e de nitrogênio inferior a $1,3 \mathrm{~g} \mathrm{dm}^{-3}$, a aplicação do composto pode aumentar ou não o teor de carbono no solo. O processo deve ser controlado pela estabilização da matéria orgânica nativa do solo. Os solos PVA-1, LA-4, LV-3, PV, PVA-4 e LVA-1 (Quadro 3), com relação C/N superior a 12 (Quadro 2), não tiveram seus teores de carbono aumentados; ao contrário dos solos LV-1 e LV-2, que apresentaram acréscimos, fato atribuído, provavelmente, à presença de matéria orgânica mais estável.

O acúmulo de matéria orgânica não deve ocorrer quando a apl icação do composto é feita em sol os com teor de carbono orgânico inferior a $12 \mathrm{~g} \mathrm{dm}^{-3}$ (ex. GX, NV-1 e RQ-2) (Quadro 3), em decorrência da alta demanda de carbono e nutrientes. No solo RQ-1, a aplicação do composto duplicou o teor de carbono, porém houve redução do teor na testemunha em relação à amostra inicial (Quadros 2 e3), indicando ter ocorrido degradação da matéria orgânica nativa desse solo durante o período de incubação. Esse resultado deve ter ocorrido em outros solos, porém em menor escala.

O carbono adi ci onado ao sol o pel o composto pode ser liberado para a atmosfera, na forma de gás carbônico, incorporado à biomassa, ou então convertido em húmus estável; porém, simultaneamente, ocorrea mineralização da matéria orgânica nativa do solo. Esta interação é denominada de efeito priming e pode tanto estimular como retardar a decomposição do húmus nativo do solo (Stevenson, 1986; Cerri et al., 1992). Trabalhando com ${ }^{14} \mathrm{C}$, Sikora \& Yakovchenko (1996) observaram que a aplicação de composto de lixo não estimulou a decomposição da matéria orgânica nativa do solo.

Os teores de carbono orgânico nas amostras de solos áci dos (Quadro 3), devido à adi ção do composto delixo exclusivamente, foram reflexos das interações entre a estabilidade da matéria orgânica nativa e da disponibilidade inicial de nutrientes nos solos (Quadro 2) sobre a decomposição da carga orgânica do composto para a formação de nova biomassa microbiana ou de fonte de energia para a síntese dessa biomassa. I sto evidencia a complexidade das inter-relações entrea matéria orgânica nativa do solo eaquela adici onada pelo composto, bem como explica a ausência de correlação entre o teor ou incremento de carbono e demais variáveis.

Os efeitos das aplicações do composto + adubo, composto + cal cário e composto + cal cário + adubo não diferiram, em nenhum dos solos, daquele da aplicação do composto de lixo isoladamente (Quadro 3), exceto para composto + adubo no solo NV-2, cujo teor de carbono foi inferior. Também não se verificou diferença entre o teor de carbono orgânico do tratamento calcário + adubo e da testemunha. Esses resultados evidenciam os benefícios da aplicação do composto de lixo sobre a conservação ou mesmo aumento do teor de matéria orgânica dos sol os ácidos.

Nos sol os al cal inos CX-1, LA-7 eLVA-2, a aplicação do composto de lixo isoladamente incrementou os teores de carbono orgânico de 3,6 a 4,5 g dm${ }^{-3}$ (Quadro 3), provocando um aumento médio de $27 \%$ em relação à testemunha. Os tratamentos: composto + adubo, composto + gesso e composto + gesso + adubo, com teores intermediários de carbono, não diferiram do composto, do gesso + adubo e da testemunha, exceto no sol o LVA-2, onde o tratamento composto + gesso foi superior à testemunha.

Nos sol os CX-2 eSS, não houve efeito da aplicação do composto de lixo (isoladamente ou não) sobre o carbono orgânicoem relaçãoà testemunha (Quadro 3); todavia, no solo CX-2, a aplicação de gesso + adubo reduziu o teor de carbono em $6 \mathrm{~g} \mathrm{dm}^{-3}(-24 \%)$, possivelmente por aumentar a disponibilidade de nutrientes, principalmente de enxofre, e de energia (carbono facilmente degradável) para o desenvolvimento da biota do solo.

Resultados concordantes aos obtidos neste trabalho foram apresentados por Hortenstine \& Rothwell (1972), Ferro Neto (1994), Sikora \& Yakovchenko (1996), Alves et al. (1999) e Oliveira (2000). De acordo com alguns desses autores, o aumento no teor de matéria orgânica tem sido proporcional à dose aplicada do composto, com efeito cumulativo em aplicações sucessivas.

A degradação da matéria orgânica apresenta três fases com uma condição final de equilíbrio dinâmico na qual a mineralização do húmus é compensada pela síntese do novo húmus. A adição de material orgânico rompe o equilíbrio eocorre degradação mais intensa da matéria orgânica nativa ou exógena, ou então de ambas, conforme o tipo, a evolução e a sucessão das diferentes comuni dades de microrganismos do solo (Stevenson, 1986; Cerri et al., 1992). Eventos semel hantes têm sido verificados em sol os tratados com composto de lixo urbano (Oliveira, 2000) e ocorreram no presente experimento, com maior ou menor intensidade conforme o solo.

Pode-se estimar, por diferença entre otratamento com composto e a testemunha (Quadro 3), que, em média, $40 \%$ do carbono total aplicado pel o composto de lixo urbano foi incorporado à matéria orgânica dos solos ácidos e $37 \%$ nos solos alcalinos. Mesmo consi derando que estes val ores sejam subestimados, esses resultados foram bem inferiores aos $95 \%$ de retenção do carbono adicionado, também como composto de lixo, relatado por Sikora \& Yakovchenko (1996) em um sol o marcado com ${ }^{14} C$; porém próximo dos $33 \%$ de retenção do carbono adicionado na forma de resíduo vegetal marcado com ${ }^{14} \mathrm{C}$, verificados por J enkinson (1965). Tais diferenças são explicadas pelo tipo, dose, relação $\mathrm{C} / \mathrm{N}$ e grau de estabilidade do composto adicionado ao solo, assim como pela 
matéria orgânica, disponibilidade de nitrogênio e fertilidade dos solos em questão e corroboram os resultados obtidos neste trabalho.

\section{Nitrogênio total}

A aplicação isolada do composto de lixo incrementou oteor denitrogênio total dos sol os ácidos de 0,10 (PVA-1) a 0,30 $\mathrm{g} \mathrm{dm}^{-3}$ (NV-1) em relaçãoà testemunha (Quadro 4), com teor médio 19 \% superior, porém não significativo nos solos LV-1, PVA-1 e RQ-2. A ampla variação no incremento de nitrogênio, causada pelo composto, pode ser atribuída à perda do nutriente por volatilização de amônia e, provavel mente, também por quimi odenitrificação (Stevenson, 1986).

Em solos ácidos, a reação ligeiramente alcalina ( $p H$ entre 4,8-7,4) causada pela aplicação do composto de lixo (Abreu J r. et al., 2000) pode favorecer a volatilização de amônia que se encontra em equilíbrio com o amônio mineralizado do material orgânico. Ademais, não obstante as condições aeróbias, o acúmulo de amônio pode ser tóxico às bactérias do gênero Nitrobacter, responsáveis pela transformação do nitrito a nitrato, promovendo acúmulo de nitrito, e este, por reações químicas com compostos orgânicos, pode ser perdido nas formas de nitrogênio mol ecular e de óxido nitroso (Smith \& Chalk, 1980).

O acúmulo de nitrogênio causado pel o composto delixo foi superior ao dotratamento cal cário + adubo mineral, exceto nos solos LV-1, LA-2, PVA-1, LA-4, PVA-3, RQ-2 eLVA-1 (Quadro4). Todavia, foi evidente o aumento do teor do nutriente pel o composto, graças à sua riqueza em compostos nitrogenados. O tratamento calcário + adubo não aumentou o teor de nitrogênio total, acredita-se, porém, que tenha contribuído para a melhoria na disponibilidade do nitrogênio inorgânico em relação à testemunha.

Quadro 4. Teores de nitrogênio total em solos ácidos, adubados com composto de lixo em combinação com calcário e adubos mi nerais, e em solos alcalinos, nos quais o calcário foi substituído por gesso

\begin{tabular}{|c|c|c|c|c|c|c|}
\hline \multirow{3}{*}{ Solo } & \multicolumn{4}{|c|}{ Composto de lixo } & \multirow{3}{*}{$\begin{array}{l}\text { Calcário } \\
\text { e adubo }\end{array}$} & \multirow{3}{*}{ Testemunha } \\
\hline & \multicolumn{2}{|c|}{ Sem calcário } & \multicolumn{2}{|c|}{ Com calcário } & & \\
\hline & Sem adubo & Com adubo & Sem adubo & Com adubo & & \\
\hline & & & $-g$ & 3 & & - \\
\hline & & & Solc & cidos & & \\
\hline $\mathrm{GX}$ & $1,47 \mathrm{~A}^{(1)}$ & $1,50 \mathrm{~A}$ & $1,43 \mathrm{~A}$ & $1,45 \mathrm{~A}$ & $1,26 \mathrm{~B}$ & $1,23 \mathrm{~B}$ \\
\hline RQ-1 & $0,77 \mathrm{~A}$ & $0,79 \mathrm{~A}$ & $0,68 \mathrm{AB}$ & $0,76 \mathrm{~A}$ & $0,59 \mathrm{BC}$ & $0,49 \mathrm{C}$ \\
\hline LA-1 & $1,91 \mathrm{~A}$ & $1,97 \mathrm{~A}$ & $1,86 \mathrm{~A}$ & $1,84 \mathrm{~A}$ & $1,68 \mathrm{~B}$ & $1,66 \mathrm{~B}$ \\
\hline LV-1 & $1,13 \mathrm{BC}$ & $1,31 \mathrm{~A}$ & $1,27 \mathrm{AB}$ & $1,31 \mathrm{~A}$ & $1,10 \mathrm{C}$ & $1,01 \mathrm{C}$ \\
\hline LV-2 & $1,25 \mathrm{~A}$ & $1,37 \mathrm{~A}$ & $1,29 \mathrm{~A}$ & $1,32 \mathrm{~A}$ & $1,10 \mathrm{~B}$ & $1,02 \mathrm{~B}$ \\
\hline LA-2 & $1,40 \mathrm{ABC}$ & $1,50 \mathrm{~A}$ & $1,33 \mathrm{BCD}$ & $1,46 \mathrm{AB}$ & $1,31 \mathrm{CD}$ & $1,22 \mathrm{D}$ \\
\hline PVA-1 & $1,35 \mathrm{AB}$ & $1,46 \mathrm{~A}$ & $1,35 \mathrm{AB}$ & $1,38 \mathrm{AB}$ & $1,29 \mathrm{~B}$ & $1,25 \mathrm{~B}$ \\
\hline LA-3 & $2,23 \mathrm{AB}$ & $2,35 \mathrm{~A}$ & $2,14 \mathrm{BC}$ & $2,26 \mathrm{AB}$ & $1,95 \mathrm{D}$ & $2,04 \mathrm{CD}$ \\
\hline LA-4 & $1,58 \mathrm{AB}$ & $1,63 \mathrm{~A}$ & $1,53 \mathrm{AB}$ & $1,61 \mathrm{AB}$ & $1,47 \mathrm{BC}$ & $1,35 \mathrm{C}$ \\
\hline NV-1 & $1,09 \mathrm{~A}$ & $1,08 \mathrm{~A}$ & $0,98 \mathrm{AB}$ & $1,06 \mathrm{~A}$ & $0,86 \mathrm{BC}$ & $0,78 \mathrm{C}$ \\
\hline LA-5 & $1,24 \mathrm{~A}$ & $1,25 \mathrm{~A}$ & $1,17 \mathrm{AB}$ & $1,25 \mathrm{~A}$ & $1,08 \mathrm{BC}$ & $0,96 \mathrm{C}$ \\
\hline PVA-2 & $1,24 \mathrm{~A}$ & $1,28 \mathrm{~A}$ & $1,20 \mathrm{AB}$ & $1,28 \mathrm{~A}$ & $1,10 \mathrm{BC}$ & $1,05 \mathrm{C}$ \\
\hline LA-6 & $1,99 \mathrm{~A}$ & $2,01 \mathrm{~A}$ & $2,02 \mathrm{~A}$ & $2,04 \mathrm{~A}$ & $1,81 \mathrm{~B}$ & $1,78 \mathrm{~B}$ \\
\hline PVA-3 & $2,55 \mathrm{ABC}$ & $2,70 \mathrm{~A}$ & $2,53 \mathrm{BC}$ & $2,68 \mathrm{AB}$ & $2,46 \mathrm{CD}$ & $2,35 \mathrm{D}$ \\
\hline LV-3 & $1,42 \mathrm{~A}$ & $1,52 \mathrm{~A}$ & $1,52 \mathrm{~A}$ & $1,50 \mathrm{~A}$ & $1,26 \mathrm{~B}$ & $1,17 \mathrm{~B}$ \\
\hline LV-4 & $1,68 \mathrm{~A}$ & $1,71 \mathrm{~A}$ & $1,62 \mathrm{~A}$ & $1,70 \mathrm{~A}$ & $1,42 \mathrm{~B}$ & $1,41 \mathrm{~B}$ \\
\hline PV & $1,54 \mathrm{~A}$ & $1,61 \mathrm{~A}$ & $1,55 \mathrm{~A}$ & $1,65 \mathrm{~A}$ & $1,32 \mathrm{~B}$ & $1,27 \mathrm{~B}$ \\
\hline PVA-4 & $1,07 \mathrm{~A}$ & $1,09 \mathrm{~A}$ & $1,05 \mathrm{AB}$ & $1,07 \mathrm{~A}$ & $0,92 \mathrm{BC}$ & $0,87 \mathrm{C}$ \\
\hline NV-2 & $2,50 \mathrm{~A}$ & $2,51 \mathrm{~A}$ & $2,44 \mathrm{AB}$ & $2,52 \mathrm{~A}$ & $2,28 \mathrm{BC}$ & $2,26 \mathrm{C}$ \\
\hline RQ-2 & $0,79 \mathrm{BC}$ & $0,94 \mathrm{~A}$ & $0,81 \mathrm{AB}$ & $0,77 \mathrm{BC}$ & $0,75 \mathrm{BC}$ & $0,68 \mathrm{C}$ \\
\hline \multirow[t]{2}{*}{ LVA-1 } & $1,37 \mathrm{AB}$ & $1,51 \mathrm{~A}$ & $1,43 \mathrm{~A}$ & $1,47 \mathrm{~A}$ & $1,25 \mathrm{BC}$ & $1,21 \mathrm{C}$ \\
\hline & \multicolumn{6}{|c|}{ Solos alcalinos } \\
\hline$C X-1$ & $1,98 \mathrm{~A}$ & $2,08 \mathrm{~A}$ & $1,99 \mathrm{~A}$ & $2,07 \mathrm{~A}$ & $1,82 \mathrm{~B}$ & $1,80 \mathrm{~B}$ \\
\hline$C X-2$ & $2,79 \mathrm{~A}$ & $2,82 \mathrm{~A}$ & $2,79 \mathrm{~A}$ & $2,88 \mathrm{~A}$ & $2,56 \mathrm{~B}$ & $2,53 \mathrm{~B}$ \\
\hline LA-7 & $1,79 \mathrm{~A}$ & $1,87 \mathrm{~A}$ & $1,76 \mathrm{AB}$ & $1,79 \mathrm{~A}$ & $1,66 \mathrm{BC}$ & $1,61 \mathrm{C}$ \\
\hline LVA-2 & $1,95 \mathrm{~A}$ & $1,91 \mathrm{~A}$ & $1,96 \mathrm{~A}$ & $2,00 \mathrm{~A}$ & $1,76 \mathrm{~B}$ & $1,66 \mathrm{~B}$ \\
\hline SS & $1,39 \mathrm{~A}$ & $1,44 \mathrm{~A}$ & $1,43 \mathrm{~A}$ & $1,42 \mathrm{~A}$ & $1,14 \mathrm{~B}$ & $1,10 \mathrm{~B}$ \\
\hline
\end{tabular}

\footnotetext{
(1) Médias seguidas de mesma letra, nas linhas, não diferem entre si pelo teste Tukey a $5 \%$.
} 
De modo geral, não houve diferença entre os tratamentos: composto, composto +adubo, composto + cal cário e composto + cal cário + adubo (Quadro 4) quanto ao teor de nitrogênio; porém a aplicação do composto +adubo apresentou teores superiores aos do composto isoladamente nos solos LV-1 e RQ-2 e foi superior aos da testemunha em todos os solos. Essa vantagem da aplicação do composto + adubo sobre o composto isoladamente foi conseqüência do efeito priming (Stevenson, 1986) e concordante com os resultados obtidos por Sikora \& Azam (1993). O efeito sinérgico do composto com o adubo nitrogenadoé derivado da mineral ização do material orgânico adicionado e não da matéria orgânica nativa do solo (Sikora \& Yakovchenko, 1996).

A adição de resíduos orgânicos pode promover maior disponibilização do nitrogênio nativo do solo em decorrência do processo simultâneo de mineralização-imobilização, especialmente quando a fração ativa da matéria orgânica for mantida em alta concentração, pela presença de material orgânico decomponível no solo (Stevenson, 1986).

Nos sol os alcalinos, a adi ção do composto de lixo incrementou o teor de nitrogênio total de $0,17 \mathrm{~g} \mathrm{dm}^{-3}$ (CX-1) a 0,30 g dm-3 (SS) (Quadro 4), em média $10 \%$ superior à testemunha. Não houve diferença noteor de nitrogênio entre os tratamentos: composto, composto + adubo, composto + gesso e composto + gesso + adubo, o que pode ser atribuído, principalmente, à volatilização de amônia e, em parte, à quimi odenitrificação (Stevenson, 1986), considerando o $\mathrm{pH}$ na faixa de 5,9 a 7,8 nestas condições (Abreu J unior et al., 2000). A aplicação de gesso + adubo não diferiu da testemunha, porém, no solo LA-7, esse tratamento foi semelhante ao do composto + gesso.

Resultados semel hantes da adição de composto sobre o nitrogênio foram relatados por Sikora \& Yakovchenko (1996) e Oliveira (2000). Porém, o êxito da aplicação agrícola do composto de lixo urbano, como adubo orgânico, depende da estabilidade de sua matéria orgânica e de suas propriedades físicas, químicas e biológicas (Xin et al., 1992; Kiehl, 1985). O composto devidamente curado deve apresentar reação entre próximo da neutralidade a alcalina e relação C/N baixa (Kiehl, 1985; Berton \& Valadares, 1991). A aplicação de composto imaturo (elevada relação $\mathrm{C} / \mathrm{N}$ ) causa a deficiência de nitrogênio no sistema sol o-planta, mediante a imobilização desse nutriente pela microbiota do solo, enquanto a aplicação de composto com relação C/N estreita, causa toxidez às plantas pel o excesso de nitrogênio mineralizado (Cardoso et al., 1995). Essas propriedades sãoalteradas conformea época do ano decoleta dolixo domi ciliar (Xin et al., 1992; Cravo et al., 1998).

Considerando retenção média de 40 \% do carbono orgânico adicionado pel o composto de lixo nos solos ácidos e de $37 \%$ nos solos alcalinos, por diferença entre o carbono no tratamento composto e testemunha (Quadro 3), e uma relação $\mathrm{C} / \mathrm{N}$ final de 10:1, houve retenção média, pela matéria orgânica, de $300 \mathrm{mg} \mathrm{dm}^{-3}$ (600 kg ha-1) de nitrogênio, nos solos ácidos, e de $278 \mathrm{mg} \mathrm{dm}^{-3}$ (556 $\mathrm{kg} \mathrm{ha}^{-1}$ ), nos solos al calinos, e mineralização de 99 e $121 \mathrm{mg} \mathrm{dm}^{-3}$ (198 e $242 \mathrm{~kg} \mathrm{ha}^{-1}$ ), respectivamente. Esses valores concordam com os resultados obtidos (Quadro 4).

Um dos maiores problemas da aplicação de doses superiores a 50 t ha-1 de composto de lixo, talvez até mais importante que a contaminação por metais pesados (Xin et al., 1992; Cravo et al., 1998), é a mineralização excessiva, com o acúmulo de nitrogênio inorgânico e, em condições de campo, lixiviação de nitrato ao longo do perfil do solo e contami nação da água subsuperficial (Oliveira et al., 2001). No solo, o problema é complexo, tanto pela diversidade de formas que o nitrogênio apresenta, dadas as transformações mediadas pelos microrganismos, quanto pelas restrições analíticas em avaliar as formas de nitrogênio, decorrentes da incubação de resíduos orgânicos, ao longo do tempo.

Recomenda-se que, para evitar problemas de excesso de nitrogênio, as aplicações sucessivas de resíduos orgânicos sejam feitas com doses anuais decrescentes até o quinto ano, quando se estabel ece equilíbrio dinâmico entre mineral ização-imobilização do nitrogênio, mantendo-sea dose constantea partir daí, ou com doses baixas em toda a superfície do solo em pequenas propriedades (Stevenson, 1986). Independentemente da situação, torna-se imprescindível o monitoramento das propriedades químicas do solo.

\section{Disponibilidade de fósforo}

O teor de fósforo disponível, obtido pelo método da resina (Raij et al., 1987), foi aumentado, em relação à testemunha, de 3,3 (GX) a $15,5 \mathrm{mg} \mathrm{dm}^{-3}$ (LV-4) pela aplicação isolada do composto de lixo nos solos ácidos (Quadro 5), com incremento médio de $200 \%$; esteefeito, porém, não foi significativo no solo GX, possivel mente pela alta capacidade de adsorção deP, enosoloLV-4, pelo al toteor deP, na testemunha, e el evado desvio-padrão do teor de P.

O aumento da disponibilidade de fósforo pela apl i cação do composto pode ser explicado pel o fósforo contido no lixo domiciliar e pela interação do aumento do pH e do aporte de matéria orgânica com a força de adsorção/dessorção do el emento nos diferentes sol os ácidos. A adsorção de fósforo nesses sol os é favor ecida pela presença de ferro ealumínio livres, óxidos hidratados de ferro, alumínio e teor e tipo de argila (Stevenson, 1986; Novais \& Smyth, 1999). Próxima à neutralidade, situação verificada para a maioria dos solos em virtude da aplicação do composto (pH de 4,8 a 7,4) (Abreu J unior et al., 2000), a adsorção é menor do que em condições áci das ou alcalinas. A matéria orgânica bloqueia os centros de adsorção do solo diminuindo a capacidade de adsorção do fósforo (N ovais \& Smyth, 1999). 
Quadro 5. Teores de fósforo disponível, extraído com resina, em solos ácidos, adubados com composto de lixo, em combinação com calcário e adubos mi nerais, e em solos alcalinos, nos quais o calcário foi substituído por gesso

\begin{tabular}{|c|c|c|c|c|c|c|}
\hline \multirow{3}{*}{ Solo } & \multicolumn{4}{|c|}{ Composto de lixo } & \multirow{3}{*}{$\begin{array}{l}\text { Calcário } \\
\text { e adubo }\end{array}$} & \multirow{3}{*}{ Testemunha } \\
\hline & \multicolumn{2}{|c|}{ Sem calcário } & \multicolumn{2}{|c|}{ Com calcário } & & \\
\hline & Sem adubo & Com adubo & Sem adubo & Com adubo & & \\
\hline & & & _ $\mathrm{mg}$ & -3 & & {[} \\
\hline & & & Solo & cidos & & \\
\hline $\mathrm{GX}$ & $14,7 \mathrm{~B}^{(1)}$ & $65,2 \mathrm{~A}$ & $16,3 \mathrm{~B}$ & $63,1 \mathrm{~A}$ & $54,5 \mathrm{~A}$ & $11,4 \mathrm{~B}$ \\
\hline RQ-1 & $16,7 \mathrm{~B}$ & $102,4 \mathrm{~A}$ & $16,8 \mathrm{~B}$ & $89,4 \mathrm{~A}$ & $95,9 \mathrm{~A}$ & $6,6 \mathrm{C}$ \\
\hline LA-1 & $14,2 \mathrm{~B}$ & $66,5 \mathrm{~A}$ & $16,6 \mathrm{~B}$ & $68,1 \mathrm{~A}$ & $53,6 \mathrm{~A}$ & $2,3 \mathrm{C}$ \\
\hline LV-1 & $18,9 \mathrm{C}$ & $68,0 \mathrm{AB}$ & $18,0 \mathrm{C}$ & $82,7 \mathrm{~A}$ & 59,8 B & $5,1 \mathrm{D}$ \\
\hline LV -2 & $14,1 \mathrm{~B}$ & $73,3 \mathrm{~A}$ & $20,1 \mathrm{~B}$ & $81,1 \mathrm{~A}$ & $78,8 \mathrm{~A}$ & $4,8 \mathrm{C}$ \\
\hline LA-2 & $16,9 \mathrm{~B}$ & $101,2 \mathrm{~A}$ & $16,6 \mathrm{~B}$ & $88,3 \mathrm{~A}$ & $81,1 \mathrm{~A}$ & $6,4 \mathrm{C}$ \\
\hline PVA-1 & $10,4 \mathrm{C}$ & $99,0 \mathrm{AB}$ & $13,8 \mathrm{C}$ & $123,1 \mathrm{~A}$ & 88,3 B & $4,9 \mathrm{D}$ \\
\hline LA-3 & $18,6 \mathrm{~B}$ & $67,9 \mathrm{~A}$ & $18,7 \mathrm{~B}$ & $77,1 \mathrm{~A}$ & $74,4 \mathrm{~A}$ & $5,2 \mathrm{C}$ \\
\hline$L A-4$ & $12,1 \mathrm{~B}$ & $79,4 \mathrm{~A}$ & $13,8 \mathrm{~B}$ & $86,9 \mathrm{~A}$ & $70,3 \mathrm{~A}$ & $4,1 \mathrm{C}$ \\
\hline $\mathrm{NV}-1$ & $13,7 \mathrm{~B}$ & $69,4 \mathrm{~A}$ & $19,1 \mathrm{~B}$ & $80,4 \mathrm{~A}$ & $72,3 \mathrm{~A}$ & $5,5 \mathrm{C}$ \\
\hline LA-5 & $16,6 \mathrm{~B}$ & $84,7 \mathrm{~A}$ & $16,4 \mathrm{~B}$ & $79,7 \mathrm{~A}$ & $68,0 \mathrm{~A}$ & $5,3 \mathrm{C}$ \\
\hline PVA-2 & $11,6 \mathrm{~B}$ & $71,0 \mathrm{~A}$ & $12,5 \mathrm{~B}$ & $74,9 \mathrm{~A}$ & $58,5 \mathrm{~A}$ & $4,3 \mathrm{C}$ \\
\hline LA-6 & $28,5 \mathrm{~B}$ & $56,2 \mathrm{~A}$ & $31,9 \mathrm{~B}$ & $70,5 \mathrm{~A}$ & $59,5 \mathrm{~A}$ & $13,8 \mathrm{C}$ \\
\hline PVA-3 & $9,2 \mathrm{~B}$ & $49,7 \mathrm{~A}$ & $10,1 \mathrm{~B}$ & $47,2 \mathrm{~A}$ & $42,9 \mathrm{~A}$ & $2,8 \mathrm{C}$ \\
\hline LV-3 & $16,3 \mathrm{~B}$ & $64,6 \mathrm{~A}$ & $16,9 \mathrm{~B}$ & $57,4 \mathrm{~A}$ & $52,2 \mathrm{~A}$ & $5,6 \mathrm{C}$ \\
\hline LV -4 & $66,6 \mathrm{BC}$ & $114,5 \mathrm{~A}$ & $72,6 \mathrm{~B}$ & $135,2 \mathrm{~A}$ & $124,6 \mathrm{~A}$ & $51,2 \mathrm{C}$ \\
\hline PV & $10,1 \mathrm{~B}$ & $80,0 \mathrm{~A}$ & $17,2 \mathrm{~B}$ & $69,1 \mathrm{~A}$ & $63,7 \mathrm{~A}$ & $3,2 \mathrm{C}$ \\
\hline PVA-4 & $11,6 \mathrm{~B}$ & $73,5 \mathrm{~A}$ & $12,9 \mathrm{~B}$ & $76,5 \mathrm{~A}$ & $68,9 \mathrm{~A}$ & $3,9 \mathrm{C}$ \\
\hline NV-2 & 26,4 B & $47,1 \mathrm{~A}$ & $26,0 \mathrm{~B}$ & $54,8 \mathrm{~A}$ & $48,8 \mathrm{~A}$ & $14,7 \mathrm{C}$ \\
\hline RQ-2 & $15,0 \mathrm{~B}$ & $45,1 \mathrm{~A}$ & $11,8 \mathrm{~B}$ & $59,7 \mathrm{~A}$ & $54,7 \mathrm{~A}$ & $3,9 \mathrm{C}$ \\
\hline \multirow[t]{2}{*}{ LVA-1 } & $15,5 \mathrm{~B}$ & $77,5 \mathrm{~A}$ & $16,6 \mathrm{~B}$ & $72,8 \mathrm{~A}$ & $57,7 \mathrm{~A}$ & $3,0 \mathrm{C}$ \\
\hline & \multicolumn{6}{|c|}{ Solos alcalinos } \\
\hline$C X-1$ & $54,9 \mathrm{C}$ & $106,1 \mathrm{~A}$ & $57,6 \mathrm{BC}$ & $95,8 \mathrm{~A}$ & $81,1 \mathrm{AB}$ & $47,0 \mathrm{C}$ \\
\hline$C X-2$ & $16,4 \mathrm{C}$ & $116,0 \mathrm{~A}$ & $16,2 \mathrm{C}$ & $84,1 \mathrm{~B}$ & 80,6 B & $8,2 \mathrm{C}$ \\
\hline LA-7 & $36,7 \mathrm{~B}$ & $86,0 \mathrm{~A}$ & $33,9 \mathrm{~B}$ & $90,3 \mathrm{~A}$ & $87,9 \mathrm{~A}$ & $26,8 \mathrm{~B}$ \\
\hline LVA-2 & $46,8 \mathrm{~B}$ & $93,2 \mathrm{~A}$ & $45,8 \mathrm{~B}$ & $97,1 \mathrm{~A}$ & $78,2 \mathrm{~A}$ & 36,1 B \\
\hline SS & 27,1 B & $94,5 \mathrm{~A}$ & 29,8 B & $80,8 \mathrm{~A}$ & $86,9 \mathrm{~A}$ & $16,9 \mathrm{~B}$ \\
\hline
\end{tabular}

(1) Médias seguidas de mesma letra, nas linhas, não diferem entre si pelo teste Tukey a $5 \%$.

Embora o tratamento com composto + calcário tenha promovido valores de $\mathrm{pH}$ superiores àqueles da aplicação isolada do composto (Abreu J unior et al., 2000), não houve diferença entre esses tratamentos quanto ao teor de fósforo disponível (Quadro 5). Todavia, no solo LV-4, o tratamento composto + calcário apresentou teor de fósforo superior à testemunha e o tratamento composto não.

Os maiores incrementos nos teores de fósforo disponível deveram-se às aplicações de composto + adubo e composto + calcário + adubo (Quadro 5), cujos teores não diferiram entre si. As diferenças entre esses dois tratamentos e a adição isolada do composto, quanto ao teor defósforo, foram causadas pel o fósforo solúvel contido no superfosfato simples. Mazur et al . (1983), aplicando $30 \mathrm{t} \mathrm{ha}^{-1}$ de composto, $150 \mathrm{~kg} \mathrm{ha}^{-1}$ de fósforo como superfosfato triplo e 2,5 t ha-1 de cal cário, verificaram diminuição noteor de fósforo disponível no sol o pel o composto +adubo, quando combinado com cal cário, e atribuíram esse efeito à formação de fosfato de ferro e alumínio de baixa solubilidade. Essas diferenças experimentais foram ocasi onadas pel as variações de sol os, de doses e dos valores de $\mathrm{pH}$ entre tratamentos.

A aplicação docal cário +adubo produziu resultados sobre o teor de fósforo semel hantes aos do composto + adubo e composto + cal cário +adubo, exceto nos solos LV-1 e PVA-1 (Quadro 5), onde o composto + cal cário + adubo foi superior, fato explicado pela menor retenção de fósforo, dada a diferença de pH dos tratamentos nesses solos. A aplicação de cal cário, notadamente no tratamento cal cário + adubo, que el evou o pH dos sol os efavoreceu a formação de fosfatos de cál cio que apresentam maior solubilidade que os fosfatos de ferro e de alumínio em meio ácido, e a adição de sulfato, contido no superfosfato si mples, quetambém 
compete pelos sítios de adsor ção (N ovais \& Smyth, 1999), aumentaram a disponibilidade de fósforo.

A aplicação do composto de lixo nos sol os al cal inos não aumentou significativamente o teor de fósforo disponível em relação à testemunha (Quadro 5) em virtude dos elevados teores iniciais de fósforo nos sol os CX-1, LA-7 e LVA-2, presença de carbonatos livres no solo CX-2 e do excesso de cátions trocáveis e de sulfato no solo SS (Quadro 2), com a formação de fosfato de cál cio insolúvel.

A disponibilidade de fósforo nos solos alcalinos aumentou nos tratamentos: composto + adubo, composto + gesso +adubo egesso + adubo unicamente pela adição do superfosfato simples, exceto no solo CX-2, onde somente o composto + adubo foi superior, explicado pela insolubilização do fósforo nos dois tratamentos que continham gesso pela interação do cál cio (carbonato) livre nesse solo (Quadro 2) e daquele fornecido no gesso como nutriente.

O fósforo mineral izado do composto adicionado ao solo pode ter sido adsorvido à sua superfície col oidal, precipitado como fosfato de alumínio e ferro, nos tratamentos com sol os áci dos, e de fosfato de cál cio, nos alcal inos, ou ainda insol ubi lizado como resultado do restabelecimento do equilíbrio de solubilidade pela solubilização de formas insolúveis de fósforo (Stevenson, 1986; Novais \& Smyth, 1999). Resultados concordantes com os obtidos neste experimento, quanto à disponibilidade de fósforo, foram verificados por Mazur et al. (1983) eAlves et al. (1999).

\section{Disponibilidade de enxofre}

A adição do composto de lixo isoladamente, nos sol os ácidos, aumentou o teor de enxofre disponível de 4,4 (LV-2) a 55,7 $\mathrm{mg} \mathrm{dm}^{-3}$ (LA-5), em relação à testemunha (Quadro 6), com incremento médio de $185 \%$. Esse efeito do composto não diferiu daquel es do composto + cal cário, exceto nos sol os LA-1, LV-2, NV-1 ePVA-3, onde o tratamento composto + cal cário apresentou maior disponibilidade de enxofre, provavelmente, pela diminuição da adsorção de sulfatos em virtude da el evação do pH (Stevenson, 1986; Vitti, 1988) pel o cal cário.

Os maiores teores de enxofre disponível foram causados pelos tratamentos: composto + adubo, composto + calcário + adubo e calcário + adubo (Quadro 6), em conseqüência da adição do superfosfato simples que contém $12 \%$ de enxofre,

Quadro 6. Teores de enxofre disponível, extraído com $\mathrm{CaCl}_{2} \mathbf{0 , 0 1} \mathrm{mol} \mathrm{L}^{-1}$, em solos ácidos, adubados com composto de lixo em combinação com calcário e adubos minerais, e em solos alcalinos, nos quais o calcário foi substituído por gesso

\begin{tabular}{|c|c|c|c|c|c|c|}
\hline \multirow{3}{*}{ Solo } & \multicolumn{4}{|c|}{ Composto de lixo } & \multirow{3}{*}{$\begin{array}{l}\text { Calcário } \\
\text { e adubo }\end{array}$} & \multirow{3}{*}{ Testemunha } \\
\hline & \multicolumn{2}{|c|}{ Sem calcário } & \multicolumn{2}{|c|}{ Com calcário } & & \\
\hline & Sem adubo & Com adubo & Sem adubo & Com adubo & & \\
\hline & & & $\mathrm{mg}$ & $1^{-3}$ & & \\
\hline & & & Solo & cidos & & \\
\hline \multirow[t]{2}{*}{$\begin{array}{l}\text { GX } \\
\text { RQ-1 } \\
\text { LA-1 } \\
\text { LV-1 } \\
\text { LV-2 } \\
\text { LA-2 } \\
\text { PVA-1 } \\
\text { LA-3 } \\
\text { LA-4 } \\
\text { NV-1 } \\
\text { LA-5 } \\
\text { PVA-2 } \\
\text { LA-6 } \\
\text { PVA-3 } \\
\text { LV-3 } \\
\text { LV-4 } \\
\text { PV } \\
\text { PVA-4 } \\
\text { NV-2 } \\
\text { RQ-2 } \\
\text { LVA-1 }\end{array}$} & $\begin{array}{l}50,9 \mathrm{C}(1) \\
35,9 \mathrm{~B} \\
45,2 \mathrm{C} \\
47,5 \mathrm{~B} \\
11,3 \mathrm{C} \\
58,2 \mathrm{~B} \\
52,1 \mathrm{~B} \\
59,5 \mathrm{~B} \\
48,8 \mathrm{~B} \\
25,5 \mathrm{C} \\
73,1 \mathrm{~B} \\
57,1 \mathrm{~B} \\
34,0 \mathrm{~B} \\
17,7 \mathrm{C} \\
15,9 \mathrm{~B} \\
50,4 \mathrm{C} \\
23,9 \mathrm{~B} \\
55,6 \mathrm{~B} \\
37,6 \mathrm{~B} \\
53,8 \mathrm{~B} \\
41,3 \mathrm{C}\end{array}$ & $\begin{array}{l}274,4 \mathrm{~A} \\
277,6 \mathrm{~A} \\
309,1 \mathrm{~A} \\
258,5 \mathrm{~A} \\
270,5 \mathrm{~A} \\
378,6 \mathrm{~A} \\
380,4 \mathrm{~A} \\
312,8 \mathrm{~A} \\
297,5 \mathrm{~A} \\
227,3 \mathrm{~A} \\
413,1 \mathrm{~A} \\
402,9 \mathrm{~A} \\
220,3 \mathrm{~A} \\
205,7 \mathrm{~A} \\
183,9 \mathrm{~A} \\
148,8 \mathrm{~A} \\
321,8 \mathrm{~A} \\
277,7 \mathrm{~A} \\
268,5 \mathrm{~A} \\
303,9 \mathrm{~A} \\
329,4 \mathrm{~A}\end{array}$ & 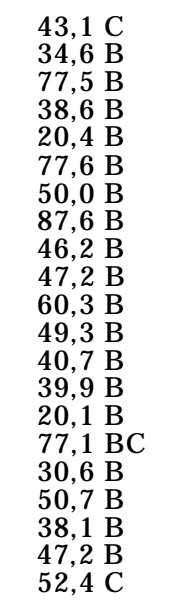 & $\begin{array}{l}255,6 \mathrm{AB} \\
242,2 \mathrm{~A} \\
378,5 \mathrm{~A} \\
299,5 \mathrm{~A} \\
266,2 \mathrm{~A} \\
392,1 \mathrm{~A} \\
362,8 \mathrm{~A} \\
382,1 \mathrm{~A} \\
300,7 \mathrm{~A} \\
228,8 \mathrm{~A} \\
376,5 \mathrm{~A} \\
365,6 \mathrm{~A} \\
238,3 \mathrm{~A} \\
201,2 \mathrm{~A} \\
184,0 \mathrm{~A} \\
162,0 \mathrm{~A} \\
295,7 \mathrm{~A} \\
317,4 \mathrm{~A} \\
272,4 \mathrm{~A} \\
345,2 \mathrm{~A} \\
296,0 \mathrm{AB}\end{array}$ & $\begin{array}{l}157,0 \mathrm{~B} \\
321,0 \mathrm{~A} \\
349,3 \mathrm{~A} \\
245,5 \mathrm{~A} \\
244,1 \mathrm{~A} \\
346,7 \mathrm{~A} \\
318,7 \mathrm{~A} \\
374,4 \mathrm{~A} \\
257,2 \mathrm{~A} \\
149,1 \mathrm{~A} \\
335,3 \mathrm{~A} \\
324,1 \mathrm{~A} \\
223,3 \mathrm{~A} \\
174,0 \mathrm{~A} \\
160,3 \mathrm{~A} \\
120,8 \mathrm{AB} \\
291,8 \mathrm{~A} \\
259,3 \mathrm{~A} \\
196,2 \mathrm{~A} \\
243,3 \mathrm{~A} \\
213,9 \mathrm{~B}\end{array}$ & $\begin{array}{r}22,6 \mathrm{D} \\
16,9 \mathrm{C} \\
11,7 \mathrm{D} \\
14,4 \mathrm{C} \\
6,9 \mathrm{D} \\
22,6 \mathrm{C} \\
16,2 \mathrm{C} \\
27,0 \mathrm{C} \\
16,4 \mathrm{C} \\
8,2 \mathrm{D} \\
17,4 \mathrm{C} \\
20,5 \mathrm{C} \\
13,1 \mathrm{C} \\
7,1 \mathrm{D} \\
8,9 \mathrm{C} \\
14,4 \mathrm{D} \\
8,5 \mathrm{C} \\
13,8 \mathrm{C} \\
11,8 \mathrm{C} \\
20,2 \mathrm{C} \\
16,1 \mathrm{D}\end{array}$ \\
\hline & \multicolumn{6}{|c|}{ Solos alcalinos } \\
\hline $\begin{array}{l}\text { CX-1 } \\
\text { CX-2 } \\
\text { LA-7 } \\
\text { LVA-2 } \\
\text { SS }\end{array}$ & $\begin{array}{r}33,1 \mathrm{C} \\
44,5 \mathrm{C} \\
43,9 \mathrm{C} \\
44,6 \mathrm{C} \\
161,2 \mathrm{C}\end{array}$ & $\begin{array}{l}141,0 \text { B } \\
341,9 \text { B } \\
170,6 \text { B } \\
144,9 \text { B } \\
465,1 \text { B }\end{array}$ & $\begin{array}{l}463,6 \mathrm{~A} \\
430,6 \mathrm{~B} \\
414,5 \mathrm{~A} \\
483,2 \mathrm{~A} \\
597,9 \mathrm{~B}\end{array}$ & $\begin{array}{l}515,5 \mathrm{~A} \\
711,1 \mathrm{~A} \\
570,4 \mathrm{~A} \\
576,3 \mathrm{~A} \\
909,6 \mathrm{~A}\end{array}$ & $\begin{array}{l}436,9 \text { A } \\
739,3 \mathrm{~A} \\
556,9 \mathrm{~A} \\
575,2 \mathrm{~A} \\
997,8 \mathrm{~A}\end{array}$ & $\begin{array}{r}12,9 \mathrm{D} \\
18,1 \mathrm{D} \\
19,9 \mathrm{D} \\
16,9 \mathrm{D} \\
151,5 \mathrm{C}\end{array}$ \\
\hline
\end{tabular}

(1) Médias seguidas de mesma letra, nas linhas, não diferem entre si pelo teste Tukey a $5 \%$. 
exceto nos solos GX e LVA-1, onde o tratamento composto + adubo foi superior ao do cal cário + adubo, provavelmente, pela menor adsorção de sulfato, decorrente da diferença de $\mathrm{pH}$ entre esses tratamentos, conforme verificado por Abreu J r. et al. (2000).

Nos solos alcalinos, excluindo o solo SS, a aplicação isolada do composto aumentou os teores de enxofre de 20,2 (CX-1) a 27,7 $\mathrm{mg} \mathrm{dm}^{-3}$ (LVA-2) (Quadro 6), com teor médio $150 \%$ superior ao da testemunha. Todavia, a aplicação do gesso, juntamente com o composto, composto +adubo e com o adubo, foi o fator preponderante no aumento da disponibilidade de enxofre, notadamente nos sol os CX-1, LA-7 eLVA-2. Teores muito el evados deS-SO ${ }_{4}^{2-}$, próximos a $1.000 \mathrm{mg} \mathrm{dm}^{-3}$, ocorreram nos tratamentos com composto + gesso + adubo e gesso + adubo no solo SS, cujo teor inicial já era el evado (Quadro 2). Os resultados demonstram um efeito acumulativo do enxofre contido no superfosfato simples e no gesso sobre a disponibilidade desse nutriente.

Supõe-se que, assi $m$ como deve ter ocorrido com o carbono e nitrogênio, o aumento no teor de S- $\mathrm{SO}_{4}{ }_{4}^{2-}$ pela aplicação do composto foi decorrente, principalmente, da mineralização da matéria orgânica do composto e não daquela do solo. Perdas de enxofre por volatilização de alguns compostos orgânicos provenientes da decomposição de metionina (Stevenson, 1986) também podem ter ocorrido.

Resultado semelhante ao do composto de lixo sobre a disponibilidade de enxofre foi verificado por Tabatabai \& Chae (1991), com lodo de esgoto.

\section{CONCLUSÕES}

1. A aplicação do composto de lixo urbano aumentou não só os teores de carbono orgânico, de nitrogênio total e de enxofre disponível de solos ácidos e alcalinos, mas também os teores de fósforo disponível de solos ácidos de diferentes regiões do Brasil.

2. A degradação da matéria orgânica e a mineralização de nitrogênio, fósforo e enxofre variaram de acordo com o tipo de solo, evolução e sucessão das diferentes comunidades demi crorganismos destes sol os, razão por que o acúmul o dematéria orgânica não constitui regra geral.

\section{LITE RATURA CITADA}

ABREU J r., C.H.; MURAOKA,T., LAVORANTE, A.F. \& ALVAREZ V., F.C. Condutividade elétrica, reação do solo e acidez potencial em solos adubados com composto lixo. R. Bras. Ci. Solo, 24:635-647, 2000.
ALVES, W.L.; MELO,W.J . \& FERREIRA, M.E. Efeito do composto de lixo urbano em um solo arenoso e em plantas de sorgo. R. Bras. Ci. Solo, 23:729-736, 1999.

BERNAL, M.P.; SÁNCHES-MONEDERO, M.A.; PAREDES, C. $\&$ ROIG, A. Carbon mineralization from organic wastes at different composting stages during their incubation with soil. Agr. Ecosyst. Environ., 69:175-189, 1998.

BERTON, R.S. \& VALADARES, J.M.A.S. Potencial agrícola do composto de lixo urbano no estado de São Paulo. O Agronômico, 43:87-93, 1991.

CARDOSO, E.J.B.N.; J AHNEL, M.C. \& MELONI, R. Avaliação do composto de lixo. In: CONGRESSO BRASILEIRO DE CIÊNCIA DO SOLO, 25., Viçosa, 1995. Resumos expandidos. Viçosa, Sociedade Brasileira de Ciência do Solo, 1995. p.2297.

CERRI, C.C.;ANDREUX, F. \& EDUARDO, B.P. O cido do carbono no solo. In: CARDOSO, E.J.B.N.; TSAI, S.M. \& NEVES, M.C.P., eds. Microbiologia do solo. Campinas, Sociedade Brasileira de Ciência do Solo, 1992. p.73-90.

CRAVO, M.S.; MURAOKA, T. \& GINÉ, M.F. Caracterização química de compostos de lixo urbano de algumas usinas brasileiras. R. Bras. Ci. Solo, 22:547-553, 1998.

EMPRESA BRASILEIRA DE PESQUISA AGROPECUÁRIA EMBRAPA. CentroNacional de Pesquisa de Solos. Sistema brasileiro de classificação de solos. Brasília, EMBRAPA Produção de I nformação; Rio de J aneiro, EMBRAPA Solos, 1999. $412 p$.

FERRO NETO,A. Produção racional de composto delixo urbano. In: SEMINÁRIO SOBRE USO DE RESÍDUOS INDUSTRIAIS E URBANOS EM FLORESTAS, 1 ., Botucatu, 1994. Trabalhos apresentados. Botucatu, Universidade Estadual Paulista, 1994. p.1-14.

HORTENSTINE, C.C. \& ROTHWELL, D.F. Use of municipal compost in reclamation of phosphate- mining sand tailings. J. Environ. Qual., 1:415-418, 1972.

J ENKINSON, D.S. Studies on decomposition of plant material in soil. I. Losses of carbon from ${ }^{14} \mathrm{C}$ labelled ryegrass incubated with soil in field. J. Soil Sci., 16:104-115, 1965.

KIEHL, E.J . Fertilizantes orgânicos. Piracicaba, Ceres, 1985. 492p.

MAZUR, N.; SANTOS, G.A. \& VELLOSO, A.C.X. Efeito do composto de resíduo urbano na disponibilidade de fósforo em solo ácido. R. Bras. Ci. Solo, 7:153-156, 1983.

NOVAIS, R.F. \& SMYTH, T.J. Fósforo em solo e planta em condições tropicais. Viçosa, U niversidadeFederal deViçosa, 1999. 399p.

OLIVEIRA, F.C. Disposição de lodo de esgoto e composto de lixo urbano num latossolo vermel ho-amarelo cultivado com cana-de-açúcar. Piracicaba, Escola Superior deAgricultura "Luiz de Queiroz", 2000. 247p. (Tese de Doutorado)

OLIVEIRA, F.C.; MATTIAZZO, M.E.; MARCIANO, C.R. \& MORAES, S.O. Percolação de nitrato em L atossol oAmarelo distrófico afetada pela aplicação de composto de lixo urbano e adubação mineral. R. Bras. Ci. Solo, 25:731-741, 2001. 
RAIJ , B. van; QUAGGIO, J.A.; CANTARELLA, H.; FERREIRA, M.E.; LOPES, A.S. \& BATAGLIA, O.C. Análise química do solo para fins de fertilidade. Campinas, Fundação Cargill, 1987. 170p.

SANTOS, R.V. Correção de um solo Salino-Sódico e absorção de nutrientes pelo feijoeiro vigna (Vigna unguiculata (L.) Walp.). Piracicaba, Escola Superior de Agricultura "Luiz de Queiroz", 1995. 120p.(Tese de Doutorado)

SAS INSTITUTE INC. SAS-Statistical analysis system (software). Cary, 1998.

SIKORA, L.J. \& AZAM, M.I. Effect of compost-fertilizer combinations on wheat yields. Compost Sci. Land Util., 1:93-96, 1993.

SIKORA, L.J. \& YAKOVCHENKO, V. Soil organic matter mineralization after compost amendment. Soil Sci. Soc. Am. J., 60:1401-1404, 1996.
STEVENSON, F.J . Cycles of soil, carbon, nitrogen, phosphorus, sulfur, micronutrientes. New York, J ohn Wiley, 1986. 380p.

SMITH, C.J . \& CHALK, P.M. Fixation and loss of nitrogen during transformations of nitrite in soils. Soil Sci. Soc. Am. J., 44:288-291, 1980.

TABATABAI, M.A. \& CHAE, Y.M. Mineralization of sulfur in soils amended with organic wastes. J. Environ. Qual., 20:684-690, 1991.

VITTI, G.C. Avaliação e interpretação do enxofre no solo e na planta. J aboticabal, Fundação de Estudos e Pesquisa em Agronomia, Medicina Veterinária e Zootecnia, 1988. 37p.

XIN, T.H.; TRAINA, S.J . \& LOGAN, T.J . Chemical properties of municipal solid waste compost. J. Environ. Qual., 21:318329, 1992.

ZONTA, E.P.; MACHADO, A.A. \& SILVEIRA J r., P. Sistemas de análise estatística para microcomputadores: manual de utilização. Pelotas, Universidade Federal de Pel otas, 1987. 145p. 